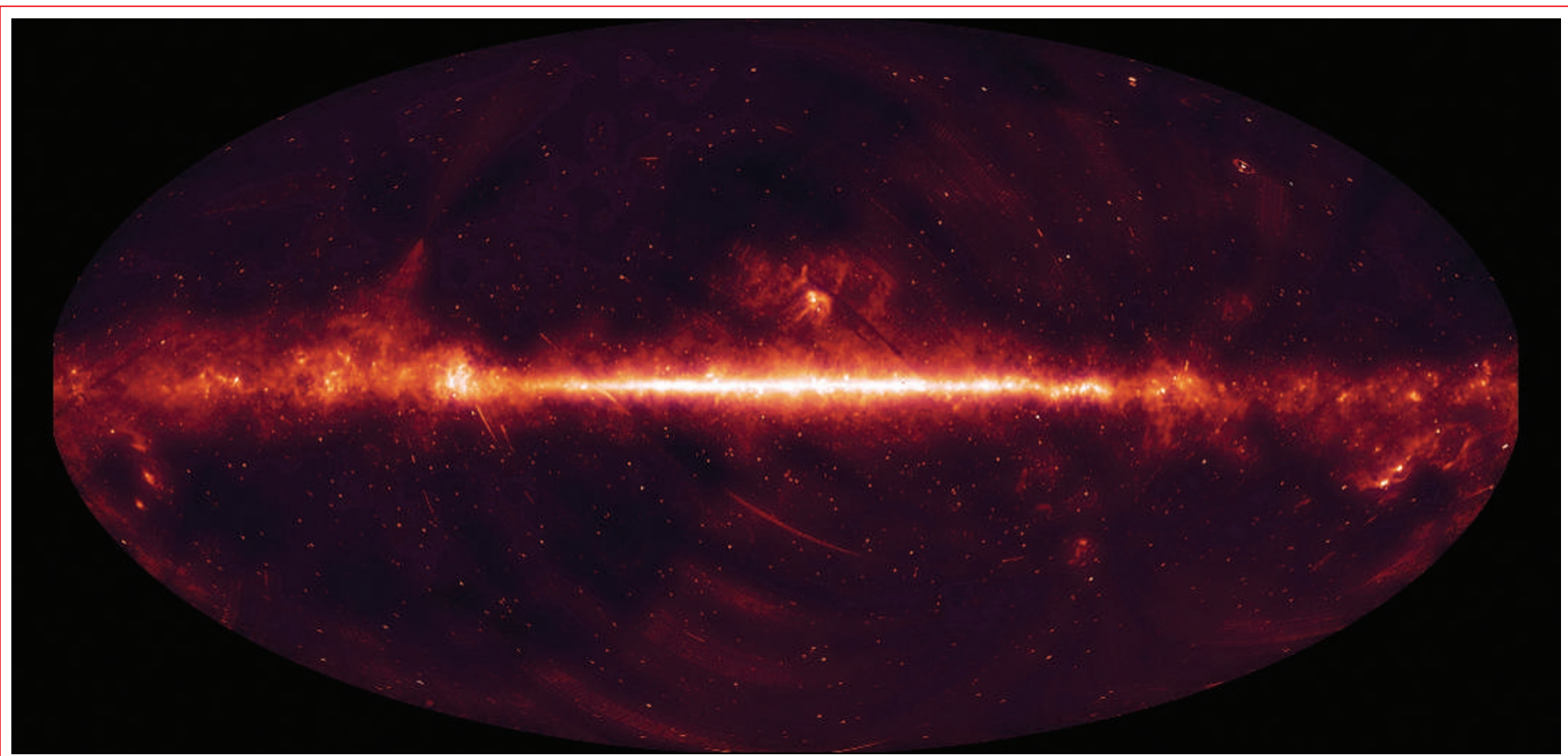

SNAPSHOT

\section{Seeing red}

The entire sky's infrared emissions are captured in this image released last week by the Japan Aerospace Exploration Agency (JAXA) and the European Space Agency (ESA). The plane of the Milky Way galaxy appears as a bright strip running through the middle, with the black hole at its heart emitting strongly. The bright spot at the lower right is the neighbouring galaxy the Large Magellanic Cloud.

This map was assembled from thousands of images taken by JAXA's AKARI satellite, which has been in orbit since February 2006. "What you are seeing now is the result of the comprehensive coverage of the entire sky, the result of a year's scanning," says team member Chris Pearson of ESA, who is based in Japan.

The latest map has a higher resolution and sensitivity than the whole-sky infrared map compiled by the Infrared Astronomical Satellite (IRAS) in 1984. Stars that were previously blurs are now distinct entities.

AKARI has also surveyed colder galaxies than IRAS was able to detect. It will keep collecting data until it runs out of the liquid helium needed to keep its detectors cold - which is expected to happen in early September 2007. David Cyranoski

\title{
Science watchdog baulks at merger
}

Members of an influential parliamentary committee, which serves as a watchdog on UK science policy, are protesting over a planned government reorganization that they fear would subsume it into a larger committee.

Under the plans, the Select Committee on Science and Technology would become part of the newly created Department for Innovation, Universities and Skills, which is responsible for science now that Gordon Brown is prime minister (see Nature 448, 7; 2007). Members worry that the new committee would be mainly concerned with university administration.

The science select committee, consisting of members of the three main political parties, is well known for overseeing the government's policy on issues ranging from illegal drugs to the proposed national identity-card scheme. Earlier this year, it also successfully campaigned to overturn the government's proposed ban on hybrid embryo research.
Given the current high public profile of science, now is "the wrong time to downgrade or reduce the scrutiny of cross-cutting science issues within parliament", committee chair Phil Willis wrote in a letter to Geoff Hoon, the government's chief whip. "The strong view amongst the science community is that such scrutiny is best carried out by a select committee with a clear identity and a clear mission."

Another committee member, Evan Harris, added: “The problem is that a committee that covers universities and skills is not going to have time to scrutinize science across the government." It would be preferable, he says, for a dedicated, independent science committee to continue with the remit of the current one.

Harris raised the possibility in parliamen- tary questions on 12 July. House of Commons leader Harriet Harman replied that "discussions are ongoing". Harris told Nature that the committee's ideal position would be to remain as an independent entity, rather than become a subcommittee within the new department.

\section{"It's a pity that the name 'science' has} been lost because it will reduce its profile. That's the danger."
Critics of the government's reshuffle have pointed out that the new department, although responsible for overseeing science, does not even feature the word 'science' in its title. "It's a pity that the name 'science' has been lost because it will reduce its profile. That's the danger," says Harris.

Previously, scientific research came under the remit of the Office of Science and Innovation, within the Department of Trade and Industry.

Michael Hopkin

See Editorial, page 226. 